\title{
Os fatores Condicionantes da Gestão de Custos Interorganizacionais em uma indústria metalúrgica da cidade de Rio do Sul - SC
}

\begin{abstract}
Sabrina do Nascimento
Doutorado em andamento em Administração pela Universidade do Vale do Itajaí -

UNIVALI

Professora e Orientadora de Curso na Faculdade de Tecnologia SENAC Florianópolis

Rua Silva Jardim, 360. Prainha. Florianópolis/SC. CEP: 88020-200

E-mail:sabnascimento@gmail.com

Alexandre Matos Pereira

Mestrado em Ciências Contábeis pela Universidade Regional de Blumenau - FURB Professor na Universidade para Desenvolvimento do Alto do Vale do Itajaí - UNIDAVI Rua Doutor Guilherme Gemballa, 13. Jardim América. Rio do Sul/SC. CEP: 89160-000

E-mail: alexandre@unidavi.edu.br

Jorge Eduardo Scarpin Doutorado em Controladoria e Contabilidade pela Universidade de São Paulo - USP Professor Adjunto na Universidade Federal do Paraná - UFPR Rua Quinze de Novembro, 1299. Centro. Curitiba/PR. CEP: 80060-000 E-mail: jorgescarpin@furb.br
\end{abstract}

\section{RESUMO}

O artigo buscou identificar os fatores condicionantes da Gestão de Custos Interorganizacionais (GCl) em uma indústria metalúrgica na cidade de Rio do Sul em Santa Catarina. Na metodologia, optou-se pela estratégia de estudo de caso numa empresa metalúrgica líder do segmento de bicicletas, com abordagem qualitativa e por meio de um conjunto formado por 5 questionários propostos por Souza (2008). Dentre os achados da pesquisa, verificou-se que em relação aos cinco fatores condicionantes analisados (i) os produtos apresentam alta funcionalidade; (ii) os componentes demonstram alto grau de restrição tecnológica e elevado índice de valor; (iii) quanto ao nível de relacionamento a empresa estabelece relações de interdependência do tipo principal, onde os fornecedores se envolvem no processo de criação, desenvolvimento e fabricação dos produtos; (iv) o tipo de cadeia que a empresa encontra-se inserida é do tipo democracia em relação aos concorrentes internacionais; e (v) os mecanismos utilizados pela empresa são do tipo capacitores. Pode se concluir que os fatores condicionantes da $\mathrm{GCl}$ estão presentes na empresa analisada e sua implementação torna-se recomendável e estimulada pela utilização de outros mecanismos que auxiliam na gestão dos custos.

Palavras-chave: Custos Interorganizacionais. Estudo de Caso. Indústria Metalúrgica. 
Os fatores Condicionantes da Gestão de custos Interorganizacionais em uma Indústria

metalúrgica da cidade de Rio do Sul - SC

Sabrina do Nascimento, Alexandre Matos Pereira, Jorge Eduardo Scarpin

\title{
Factors conditionants of the management of interorganizationals costs in a metallurgic industry of the city of Rio do Sul - SC
}

\begin{abstract}
The article searched to identify the condicionants factors of the Management of Interorganizationals Costs (MIC) in a metallurgic industry in the city of Rio do Sul in Santa Catarina, Brazil. The methodology is based on the strategy of case study in a leader metallurgic company of the segment of bicycles, with qualitative boarding and by means of a set formed for 5 questionnaires considered for Souza (2008). Among the findings of the research, it was verified that in relation to the five conditionants factors analyzed: (i) the products present high functionality; (ii) the components demonstrate high degree of technological restriction and raised value index; (iii) how much to the relationship level the company establishes relations of interdependence of the main type, where the suppliers involve in the process of creation, development and manufacture of the products; (iv) the type of chain that the company meets inserted is of the type democracy in relation to the international competitors; e (v) the mechanisms used for the company are of the type capacitors. It can be conclude that the conditionants factors of the MIC are gifts in the analyzed company and its implementation becomes recommendable and stimulated for the use of other mechanisms that assist in the management of the costs.
\end{abstract}

Keywords: Interorganizationals costs. Case Study. Metallurgic industry.

\section{INTRODUÇÃO}

As empresas estão inseridas em um ambiente altamente dinâmico, onde encontrar uma vantagem competitiva sustentável tem se tornado um fator imprescindível a sua sobrevivência. A vantagem competitiva pode ser conquistada a partir do reconhecimento das ligações existente entre as empresas, principalmente na cadeia de valor na qual ela está inserida. Essas ligações ou interligações entre as organizações influenciam a concepção, projeto e o desenvolvimento dos produtos que ela venha a produzir ampliando assim o quadro de possibilidades no processo de gestão interorganizacional. Assim, gerenciar as influências torna-se estratégico e pode 
Os fatores Condicionantes da Gestão de custos Interorganizacionais em uma Indústria

metalúrgica da cidade de Rio do Sul - SC

Sabrina do Nascimento, Alexandre Matos Pereira, Jorge Eduardo Scarpin

acarretar em ganhos ou evitar perdas para as empresas que permeiam uma determinada cadeia de valor (SOUZA; ROCHA, 2008b). Os autores destacam ainda que "uma gestão eficiente e eficaz dos relacionamentos pode minimizar os custos de transações para as organizações, como, por exemplo, evitando-se o custo de procura e contratação de um novo parceiro" (SOUZA; ROCHA, 2008b, p. 65).

Considerando esse cenário, as empresas devem ser vistas como ligações de uma cadeia de produção e/ou cadeia de valor, onde é necessário que ela mantenha um relacionamento com as demais empresas que executam as atividades relevantes da sua cadeia, buscando obter a eficiência da cadeia como um todo. Nas relações provenientes dessa cadeia de produção, um dos fatores-chave para obtenção de melhorias para toda a cadeia são essas ligações e não gera vantagens apenas para as algumas empresas que a compõem (MEIRA; WANDERLEY; MIRANDA, 2005).

De acordo com Saraiva Júnior, Rodrigues e Costa (2009, p.2) “a abertura de mercado e o rápido desenvolvimento de novas tecnologias têm impactado de maneira decisiva as organizações, fazendo-as buscar novas metodologias de gestão que as tornem mais competitivas". Assim, buscando proporcionar vantagem competitiva sustentável às empresas algumas ferramentas gerenciais podem ser utilizadas, sendo uma dessas a Gestão de Custos Interorganizacionais (GCl). Souza e Rocha (2007, p. 2) conceituam a $\mathrm{GCl}$ como "um processo cooperativo de gerenciamento de custos que inclui outras organizações dentro de uma cadeia de valor além da própria empresa". Aguiar, Rezende e Rocha (2008, p.2) mencionam que "a implementação (...) requer um conjunto de variáveis tais como o posicionamento estratégico, a utilização de instrumentos da Gestão Estratégica de Custos e o compartilhamento de informações e de resultados". Os autores salientam, ainda, que essa metodologia caracteriza-se pela possibilidade de as empresas utilizarem a gestão estratégica de custos compartilhada, criando novas tecnologias gerando vantagem para as organizações que a utilizam (AGUIAR; REZENDE; ROCHA, 2008). Para tanto, Aguiar e Rocha (2007, p.1) salientam que "a obtenção da vantagem competitiva e a criação de valor exigem tanto melhoria 
nos processos internos quanto aperfeiçoamento nos relacionamentos com os membros que integram sua cadeia de valor". Cabe mencionar, que este tema ainda é incipiente na literatura acadêmica, sendo que alguns dos principais estudos que o abordam são elaborados por Cooper e Slagmulder (2004); Bitti, Aquino e Pagliarussi (2007); Aguiar e Rocha (2007); Souza (2008); Souza e Rocha (2008a) e Souza e Rocha (2008b).

Nesse contexto, a partir da importância de se conhecer e explorar essa metodologia e os fatores condicionantes de sua implantação nas organizações, emerge a indagação que norteia a presente pesquisa: Quais os fatores condicionantes da Gestão de Custos Interorganizacionais em uma empresa metalúrgica? Assim, tem-se como objetivo principal identificar os fatores condicionantes da Gestão de Custos Interorganizacionais $(\mathrm{GCl})$ em uma indústria metalúrgica na cidade de Rio do Sul em Santa Catarina.

Esta pesquisa justifica-se ao proporcionar subsídios para a discussão acerca da aplicação da $\mathrm{GCl}$ na gestão de sua cadeia de valor e na obtenção de vantagem competitiva. Aguiar, Rezende e Rocha (2008, p. 67) destacam que pesquisas assim podem auxiliar os gestores "no sentido de evitar que implementem essa técnica gerencial apenas por isomorfismo, mas que a sua implementação possa de fato contribuir para a obtenção de vantagens competitivas e criação de valor". Souza (2008, p. 17) salienta que foi identificada uma carência de "investigações científicas sobre esse tema, e outro fator que contribui para acentuar a necessidade de se entender esse tipo de mecanismo de controle: diferenças institucionais".

O presente estudo inicia-se por esta seção de caráter introdutório, na seqüência a seção 2 que fornece a sustentação teórica sobre a Gestão de Custos Interorganizacionais $(\mathrm{GCl})$ e seus fatores condicionantes, seguida pela metodologia. Posteriormente, na seção 4 aparece a análise e discussão dos resultados observados na empresa metalúrgica estudada, e por fim, na seção 5 são apresentadas as considerações finais e as sugestões para futuras pesquisas. 
Os fatores Condicionantes da Gestão de custos Interorganizacionais em uma Indústria

metalúrgica da cidade de Rio do Sul - SC

Sabrina do Nascimento, Alexandre Matos Pereira, Jorge Eduardo Scarpin

\section{GESTÃO DE CUSTOS INTERORGANIZACIONAIS E OS FATORES CONDICIONANTES}

A Gestão de Custos Interorganizacionais $(\mathrm{GCl})$ tem por objetivo "encontrar soluções através de ações coordenadas entre as organizações da cadeia, o que não seria possível se as empresas tentassem reduzir custos independentemente" (SOUZA; ROCHA, 2008, p.2). Aguiar, Rezende e Rocha (2008, p.3) destacam que a $\mathrm{GCl}$ requer importantes pressupostas para a gestão da cadeia de valor, em que o relacionamento entre os fornecedores e empresas líderes da cadeia representa seu foco de estudo. Assim, para a aplicação da $\mathrm{GCl}$, cinco fatores condicionantes tornam-se fundamentais, sendo eles: produtos, componentes, níveis de relacionamento, tipos de cadeia e mecanismos. Com vistas, a elucidar cada um dos cinco fatores condicionantes de maneira mais aprofundada, comenta-se a seguir sobre cada um deles de forma isolada.

a) Fator Condicionante Produtos - o fator caracteriza-se pelo bem ofertado pela empresa, sendo ele um produto ou serviço. Neste item verificam-se as características eminentes de cada produto, sendo dois os indicadores principais para sua análise: a margem (rentabilidade que o produto traz para a empresa) e a funcionalidade (qualidade e a implementação de novas tecnologias aos produtos), tendo como principal objetivo identificar o tipo de produto onde a aplicação da $\mathrm{GCl}$ é recomendada (SOUZA, 2008);

b) Fator Condicionante Componentes - este fator compreende os itens que compõem o produto. A empresa pode optar por realizar a $\mathrm{GCl}$ apenas nos componentes que julgar mais importantes. Conforme Souza (2008), duas características devem ser analisadas neste fator: o índice de valor (relaciona-se com o custo $\mathrm{x}$ benefício trazido pelo componente) e a restrição tecnológica (relaciona-se com a tecnologia desenvolvida pela empresa que deve ser mantida em sigilo e qual pode ser compartilhada com outras empresas); 
c) Fator Condicionante Níveis de Relacionamento - Este fator condicionante busca analisar os níveis de relacionamentos existentes no trato com os fornecedores, tendo os seguintes níveis: comum, auxiliar, principal e familiar. Para Souza e Rocha (2008), no nível comum encontram-se as inter-relações entre uma empresa e outra com vistas a comprar produtos ou para vendê-los, configurandose como o menor nível de interdependência entre elas sendo inviável a aplicação da GCl. Entretanto, o nível auxiliar demonstra um nível de interdependência maior que a categoria comum, pois geralmente uma empresa precisa de outra para a fabricação de um produto de acordo com suas especificações e necessidades, fazendo que a aplicação da $\mathrm{GCl}$ se torne possível. Para tanto, o nível principal apresenta as relações de interdependência maior que no nível auxiliar, na qual uma empresa estabelece um relacionamento que envolve além do processo de fabricação o processo de criação e desenvolvimento do produto, tendo assim contratos de longo prazo estabelecidos tornando a aplicação da $\mathrm{GCl}$ provável. E, por fim, o nível familiar apresenta o maior nível de interdependência, visto que as relações estabelecidas baseiam-se na parceria de longo prazo e na confiança, na união de esforços, desenvolvimento e melhoramento dos produtos entre as partes envolvidas. Nesses casos, a aplicação da GCl torna-se aplicável e perfeitamente recomendável;

d) Fator Condicionante Tipos de Cadeia - O entendimento do fator tipo de cadeia perpassa pelo entendimento do conceito cadeia de valor. Esta é definida por Shank e Govidaranjan (1997, p.14) como "sendo o conjunto interligado de todas as atividades que agregam valor ao consumidor final, desde fontes básicas de matéria-prima, passando por fornecedores de componentes, até a entrega do produto final às suas mãos”. De acordo com Souza (2008), as cadeias de valor podem ser categorizadas segundo a estrutura do mercado em que estão inseridas. Nesse sentido, levando em consideração estas estruturas, as cadeias de valor podem ser classificadas em três tipos: tirania, oligarquia e democracia. A 
tirania caracteriza-se pelas cadeias em que somente uma empresa tem o poder de dominar a cadeia como um todo, sendo que o seu poder de imposição é alto. $\mathrm{Na}$ oligarquia, a cadeia de valor é dominada por poucas empresas, assim o poder de imposição é relativamente alto, sendo compartilhado entre poucas empresas. E na democracia, nenhuma empresa ou mesmo um pequeno grupo de empresas comanda a cadeia de valor, assim nenhuma empresa tem poder de imposição sobre as demais; e

e) Fator Condicionante Mecanismos - Este fator condicionante tem por objetivo ajudar as empresas a escolherem mecanismos de controle da $\mathrm{GCl}$ para auxiliarem na gestão dos custos entre as empresas para conseguirem orientar, controlar, medir, informar, dar transparência buscando a GCI (SOUZA, 2008). Assim, os mecanismos podem ser divididos em três grandes grupos sendo eles: disciplinadores, capacitores e incentivadores. Os disciplinadores buscam regrar, adestrar, desenvolver e criar obrigações que regem o relacionamento entre as empresas que adotam a $\mathrm{GCl}$ com intuito de observar e corrigir aspectos fora de certas restrições (SOUZA, 2008), como exemplos podem ser citados o Open Book Accountig (OBA), Service Level Agreement (SLA) e o Custeio-alvo. Para tanto, os capacitores de acordo com Souza (2008b, p.72) "são instrumentos que fornecem capacidade, competências e possibilidades, com o objetivo de sanar dificuldades no processo de $\mathrm{GCl}$ e ajudar a resolver os problemas encontrados". Como exemplos de capacitores têm-se: intercâmbio de profissionais, financiamento, desenvolvimento em conjunto. E, por fim, os incentivadores "são os instrumentos que gratificam as partes, utilizados posteriormente ao alcance de metas estipuladas, para premiar e remunerar pelo objetivo alcançado; podem ser monetários (...) ou não monetários" (SOUZA, 2008, p.72).

No âmbito deste estudo, destacam-se algumas pesquisas empíricas nacionais e internacionais publicadas que denotam preocupação similar como de Cooper e 
Slagmulder (2004), Bitti, Aquino e Pagliarussi (2007), Aguiar e Rocha (2007), Souza (2008), Souza e Rocha (2008).

Cooper e Slagmulder (2004) estudaram a questão dos custos que transpõem as fronteiras organizacionais entre compradores e fornecedores, cujo objetivo principal é a redução dos custos por meio da Gestão de Custos Interorganizacionais durante a concepção dos produtos $\mathrm{e}$ as características dos contextos a que eles estão associados, além de discutir suas implicações na tomada de decisão. Os resultados apontam as várias relações entre a gestão dos custos e as empresas analisadas, sugerindo que a pesquisa fosse replicada em empresas diferentes com amostras maiores, visando generalizar os resultados.

Bitti, Aquino e Pagliarussi (2007) elucidaram o caso da decisão do uso simultâneo de lojas próprias e franqueadas, como um equilíbrio, numa condição de minimização de custos de monitoramento, conceituada pela Teoria da Agência. Assim, analisaram 175 redes de franchising brasileiras para testar a influência dos custos de agência na escolha de estabelecer uma loja própria e/ou franqueada. Os autores concluíram que os direcionadores de custos de monitoramento para as redes devem incluir a dispersão geográfica e a localização das lojas.

Aguiar e Rocha (2007) buscaram desenvolver uma análise do relacionamento entre a estrutura conceitual da abordagem da Gestão de Custos Interorganizacionais proposta por Cooper e Slagmulder (1999) e o Open-Book Accounting. Os resultados mostram que a implementação eficaz do modelo é moderada por um ambiente de Open-Book Accounting que pode ocorrer em situações específicas dentro de três dimensões: fatores específicos endógenos, fatores específicos exógenos e fatores específicos da rede.

Souza (2008) desenvolveu uma análise descritiva da estrutura conceitual da abordagem de Gestão de Custos Interorganizacionais (GCl) por meio da observação de duas empresas-casos em duas cadeias de organizações distintas. Nos achados da 
pesquisa foram detectados os cinco fatores condicionantes da $\mathrm{GCl}$, além de relacionálos com a aplicação nas empresas analisadas.

Souza e Rocha (2008) desenvolveram m uma análise crítica e argumentativa, para sistematizar o conhecimento sobre a Gestão de Custos Interorganizacionais e testar a aderência dos seus fatores condicionantes em duas cadeias de organizações distintas. Os autores constataram que nos dois casos analisados foram encontrados cinco fatores condicionantes sendo eles: produtos, componentes, níveis de relacionamento, tipos de cadeias e mecanismos. Estes autores analisaram, também, as implicações da $\mathrm{GCl}$ no ambiente interno e externo das empresas, relacionando-os com a teoria de base da GCI. Por meio deste estudo os autores concluem que considerando as fusões, incorporações e o crescente ritmo de internacionalização das empresas a GCl "pode ser implementada de forma que se encontrem soluções não só entre empresas, mas, também entre grupos econômicos (empresas ligadas sob o mesmo controle) ".

\section{METODOLOGIA DA PESQUISA}

A pesquisa realizada configura-se como descritiva uma vez que busca identificar os fatores condicionantes da Gestão de Custos Interorganizacionais (GCl) em uma indústria metalúrgica na cidade de Rio do Sul em Santa Catarina. Martins e Theóphilo (2007, p. 61) salientam que neste estudo "o pesquisador não tem controle sobre os eventos e variáveis, buscando aprender a totalidade de uma situação e, criticamente, descrever, compreender e interpretar a complexidade de um caso concreto". Gil (1999, p. 70) menciona que esta abordagem permite "descrever as características de determinada população ou fenômeno ou estabelecimento de relações entre as variáveis".

Quanto à amostra, optou-se pela estratégia de estudo de caso com uma abordagem qualitativa dos dados. Richardson (1999) afirma que ao contrário da 
pesquisa quantitativa que busca a quantificação dos dados, a pesquisa qualitativa descreve a complexidade de determinado problema, analisa a interação de certas variáveis, compreende e classifica processos dinâmicos vividos por grupos sociais. Martins e Theóphilo (2007, p.61) ressaltam que neste tipo de pesquisa "o pesquisador não tem controle sobre os eventos e variáveis, buscando aprender a totalidade de uma situação e, criticamente, descrever, compreender e interpretar a complexidade de um caso concreto".

Nesse contexto, a empresa objeto desse estudo, cujo nome não é declinado para preservar a identificação das suas estratégias, foi escolhida de maneira intencional, tendo como critério de seleção a acessibilidade das informações. O estudo investiga uma das maiores fabricantes de selins e pedais da América Latina com sede na cidade de Rio do Sul em Santa Catarina, que nasceu da união de duas grandes empresas do ramo de bicicletas uma empresa catarinense e a outra italiana e iniciou suas atividades em 1985. Destaca-se, ainda, que a empresa conta com um laboratório e equipamentos de altíssima qualidade para assegurar sua política e busca constantemente satisfazer seus clientes, fornecedores e colaboradores.

Selecionada a empresa, o procedimento adotado para a coleta dos dados foi de origem primária, por meio de um conjunto de 5 questionários propostos por Souza (2008). Richardson (1999) afirma que os dados primários de uma pesquisa são aqueles obtidos diretamente em campo, ou seja, na empresa metalúrgica analisada. A seguir, a Figura 1 contém as etapas executadas na consecução da presente pesquisa. 
Os fatores Condicionantes da Gestão de custos Interorganizacionais em uma Indústria

metalúrgica da cidade de Rio do Sul - SC

Sabrina do Nascimento, Alexandre Matos Pereira, Jorge Eduardo Scarpin

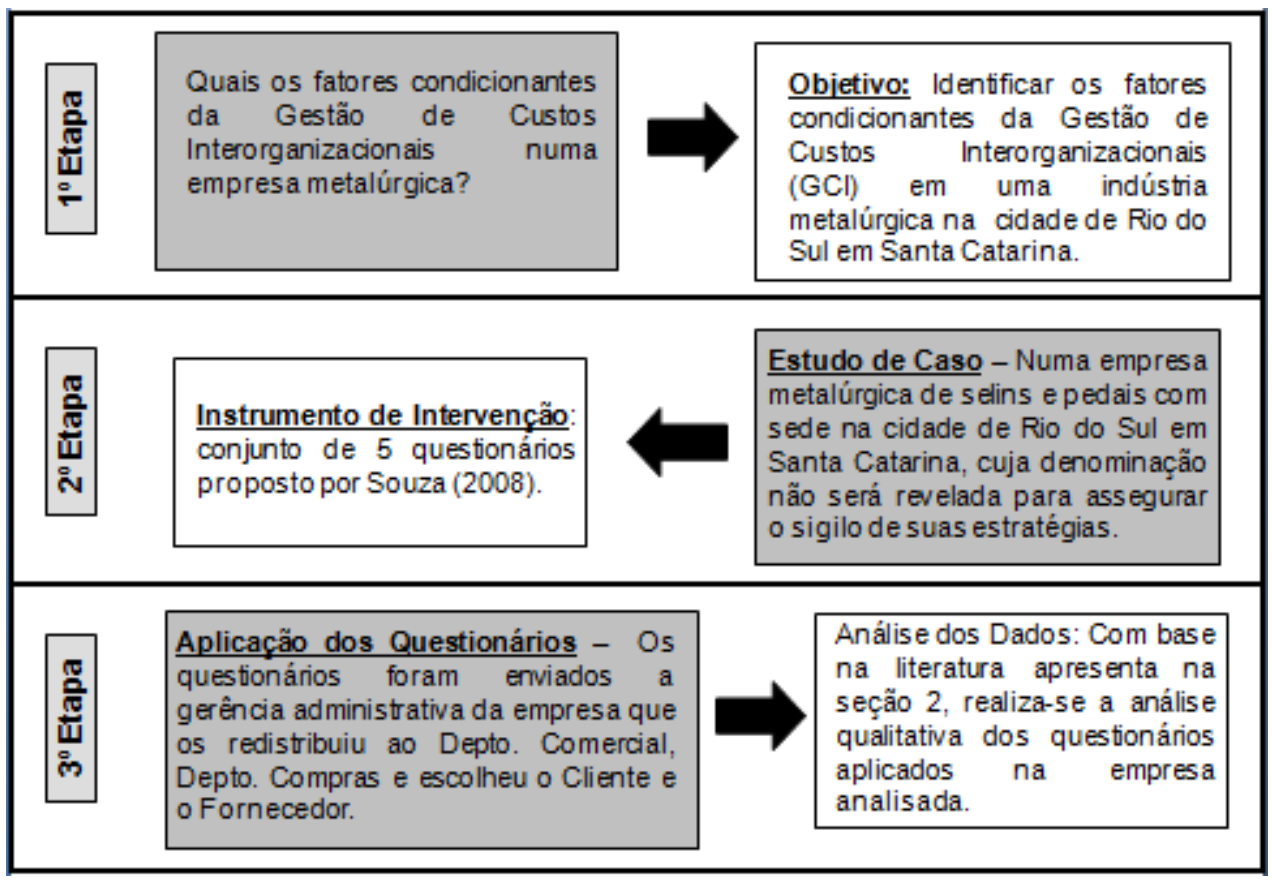

Figura 1: Etapas executadas na consecução da presente pesquisa

Fonte: Elaborado pelos autores.

Os questionários foram encaminhados no segundo semestre de 2009 via correio eletrônico à gerência administrativa da empresa analisada e esta respondeu a um questionário e redirecionou dois questionários aos responsáveis, sendo um do departamento de compras e outro do comercial. Na sequência, a gerência administrativa selecionou um cliente e um fornecedor que possuíam mais afinidade com a empresa e encaminhou os outros dois questionários para serem respondidos, sendo que todos os cinco foram devolvidos em novembro de 2009. Os questionários foram encaminhados para: a) administração da empresa com 18 perguntas abertas; b) departamento responsável pelo relacionamento com os fornecedores (Depto. Compras); c) departamento responsável pelo relacionamento com os clientes (Depto. Comercial); d) fornecedor da empresa; e f) cliente da empresa analisada, sendo todos compostos por 10 perguntas abertas respectivamente. Nesse contexto, têm-se como limitações da presente pesquisa: i) os questionários não foram respondidos na 
Os fatores Condicionantes da Gestão de custos Interorganizacionais em uma Indústria

metalúrgica da cidade de Rio do Sul - SC

Sabrina do Nascimento, Alexandre Matos Pereira, Jorge Eduardo Scarpin

presença dos pesquisadores; e ii) a empresa analisada escolheu o fornecedor e o cliente tendo em vista sua afinidade para responder ao instrumento de pesquisa.

\section{ANÁLISE DOS DADOS}

Apresenta-se nesta seção o detalhamento dos fatores condicionantes da Gestão de Custos Interorganizacionais ( $\mathrm{GCl}$ ) na empresa metalúrgica na cidade de Rio do Sul em Santa Catarina. Optou-se por dividir a seção de acordo com os fatores condicionantes, sendo eles: Produtos, Componentes, Níveis de relacionamento, Tipos de Cadeia e Mecanismos.

\subsection{Produtos e Componentes}

Esta subseção contempla as repostas dos entrevistados relacionadas aos fatores condicionantes Produtos e Componentes. Os produtos correspondem à linha de produtos (selim, pedal, guidão e descanso) fabricada pela empresa metalurgia estudada que se destinam ao mundo bike, agregando tecnologia e know-how europeus trazidos da Itália para o mercado nacional. Quanto ao fator Componentes, estes são os itens que compõem as linhas dos produtos mencionados acima. O Quadro 1 apresenta as respostas relacionadas aos fatores condicionantes Produtos e Componentes. 
Os fatores Condicionantes da Gestão de custos Interorganizacionais em uma Indústria

metalúrgica da cidade de Rio do Sul - SC

Sabrina do Nascimento, Alexandre Matos Pereira, Jorge Eduardo Scarpin

\begin{tabular}{|c|c|c|}
\hline RESPONDENTE & PERGUNTA & RESPOSTA \\
\hline $\begin{array}{c}\text { Gerência } \\
\text { Administrativa }\end{array}$ & $\begin{array}{l}\text { Os produtos da empresa são } \\
\text { vistos pelo mercado como } \\
\text { produtos de alta qualidade? E } \\
\text { alta funcionalidade? }\end{array}$ & $\begin{array}{c}\text { Sim, pois a empresa possui uma imagem } \\
\text { sólida construída ao longo dos anos de sua } \\
\text { existência. }\end{array}$ \\
\hline $\begin{array}{c}\text { Gerência } \\
\text { Administrativa }\end{array}$ & $\begin{array}{c}\text { Os produtos (ou componentes) } \\
\text { da empresa tem tecnologia } \\
\text { que deve ser preservada } \\
\text { internamente? }\end{array}$ & $\begin{array}{l}\text { Possuem inclusive tecnologia advinda da } \\
\text { empresa parceira, que é da Itália. }\end{array}$ \\
\hline Depto. Comercial & $\begin{array}{l}\text { O produto (ou componente) } \\
\text { vendido pela empresa é } \\
\text { essencial ao negócio (ou } \\
\text { produto) dos clientes? São } \\
\text { vistos como produtos de alta } \\
\text { qualidade e alta } \\
\text { funcionalidade? }\end{array}$ & $\begin{array}{l}\text { Os produtos direcionados as montadoras são } \\
\text { essenciais, pois são adquiridos como } \\
\text { matérias primas, fazem parte diretamente em } \\
\text { seus produtos. Todos são vistos como } \\
\text { produtos de alta qualidade e alta } \\
\text { funcionalidade porque atendem as } \\
\text { expectativas dos clientes. }\end{array}$ \\
\hline Cliente & $\begin{array}{l}\text { Os produtos vendidos pela } \\
\text { organização foco são } \\
\text { essenciais ao negócio (ou } \\
\text { produto) da sua empresa? São } \\
\text { vistos como produtos de alta } \\
\text { qualidade e alta } \\
\text { funcionalidade? }\end{array}$ & $\begin{array}{c}\text { Os produtos comprados da empresa } \\
\text { analisada são fundamentais em nosso } \\
\text { produto, eles entram como matéria-prima } \\
\text { para a empresa. São vistos como produtos } \\
\text { de altíssima qualidade e funcionalidade. Sem } \\
\text { estes itens (selins e pedais) não } \\
\text { conseguimos entregar nosso produto final. } \\
\text { Ocorrendo qualquer tipo de atraso ou lotes } \\
\text { reprovados nossa produção é diretamente } \\
\text { afetada. }\end{array}$ \\
\hline Fornecedor & $\begin{array}{l}\text { Há inovações freqüentes e } \\
\text { importantes na linha de seus } \\
\text { insumos? Quanto às } \\
\text { inovações? }\end{array}$ & $\begin{array}{c}\text { Esta é a nossa maior fonte de trabalho onde } \\
\text { estamos com uma demanda muito crescente } \\
\text { de mercado. Estamos cada dia melhorando } \\
\text { nossos desempenhos medindo qualidade } \\
\text { para inovar e melhorar nossa linha de } \\
\text { produtos cada vez mais }\end{array}$ \\
\hline Fornecedor & $\begin{array}{l}\text { Os insumos vendidos pela } \\
\text { empresa são essenciais ao } \\
\text { negócio (ou produto) da } \\
\text { organização foco? São Vistos } \\
\text { como produtos de alta } \\
\text { qualidade e alta } \\
\text { funcionalidade? }\end{array}$ & $\begin{array}{l}\text { Todos os produtos são essenciais para a } \\
\text { empresa mesmo que ele de uma margem } \\
\text { muito pequena de lucro ele não pode deixar } \\
\text { de ser feito. Estamos com a visão de ter todo } \\
\text { produto como crítico, não importando o } \\
\text { cliente e nem a demanda, mas sim a } \\
\text { qualidade final e satisfação do cliente. }\end{array}$ \\
\hline Depto. Compras & $\begin{array}{l}\text { O seu produto tem insumo } \\
\text { essencial comprado de } \\
\text { terceiros? Quais são os } \\
\text { insumos e de quais } \\
\text { fornecedores? }\end{array}$ & $\begin{array}{c}\text { Sim. São eles: Copolímero reciclado } \\
\text { (Plastirio), Arame BTC 12,20mm (Belgo } \\
\text { Bekaert), Isocianato, Poliol (Bayer) e as } \\
\text { chapas de aço com diversas medidas } \\
\text { (Mangels). }\end{array}$ \\
\hline
\end{tabular}

Quadro 1 - Respostas relacionadas aos fatores condicionantes Produtos e Componentes Fonte: Adaptado de Souza (2008). 
De acordo com as informações evidenciadas no Quadro 1, percebe-se que a empresa analisada fabrica produtos de alta qualidade com tecnologia própria advinda de sua parceria com uma empresa italiana. Conforme evidenciado pelo Depto. Comercial e pelo Cliente, os produtos fornecidos pela empresa estudada são de altíssima qualidade, sendo essenciais aos negócios de seus clientes como os itens: selins e pedais. Assim, dentre os insumos essenciais adquiridos pela empresa estão: Copolímero reciclado (Plastirio), Arame BTC 12,20mm (Belgo Bekaert), Isocianato, Poliol (Bayer) e as chapas de aço com diversas medidas (Mangels). Segundo o Fornecedor os produtos fornecidos a indústria metalúrgica analisada é essencial ao seu processo de fabricação, além de serem de alta qualidade e conter constantes inovações tecnológicas.

Nesse sentido, verifica-se no fator condicionante produto relacionado à funcionalidade, a tecnologia e a qualidade são uma fonte de diferenciação da empresa frente aos seus concorrentes por fornecer matéria-prima de qualidade a seus clientes, conforme destacado no Quadro 1 pelo cliente. Para tanto, com relação ao outro fator de análise dos produtos a margem a empresa estudada realiza seus controles de custos com base em demonstrativos financeiros apresentados pela contabilidade, sendo eles: Balanço Patrimonial, Demonstração do Fluxo de Caixa e Demonstração do Resultado do Exercício, não dispondo de um controle efetivo mais voltado à gestão dos custos. Para tanto, com relação ao fator condicionante componentes, observa-se que o índice de valor é retratado pelos clientes tendo em vista o custo $\mathrm{x}$ benefício trazido pelos componentes utilizados relacionados com o alto padrão tecnológico de seus produtos, tanto que a empresa dispõe de laboratórios para o desenvolvimento de seus produtos. Destaca-se, ainda, que a empresa estudada possui restrições tecnológicas por ser uma das líderes do segmento na América Latina e não pode compartilhar todas as informações com terceiros. Assim, diante do contexto observado a aplicação da GCl torna-se recomendável. Esses resultados corroboram com Souza (2008) quando este analisou uma empresa do segmento de prestação se serviços aéreos e verificou que 
Os fatores Condicionantes da Gestão de custos Interorganizacionais em uma Indústria

metalúrgica da cidade de Rio do Sul - SC

Sabrina do Nascimento, Alexandre Matos Pereira, Jorge Eduardo Scarpin

esta também possuía produtos cuja aplicação da GCl é recomendada, tendo em vista o alto nível de funcionalidades que geram oportunidades de relacionamentos futuros.

\subsection{Níveis de Relacionamento e Tipos de Cadeia}

Neste item abordam-se os fatores condicionantes de níveis de Relacionamento e os tipos de cadeia, por meio das respostas dos entrevistados, dispostas no Quadro 2.

\begin{tabular}{|c|c|c|}
\hline RESPONDENTE & PERGUNTA & RESPOSTA \\
\hline $\begin{array}{c}\text { Gerência } \\
\text { Administrativa }\end{array}$ & \multirow{3}{*}{$\begin{array}{l}\text { A empresa classifica } \\
\text { seus fornecedores? } \\
\text { Como é feita essa } \\
\text { classificação (inter- } \\
\text { relação, tempo de } \\
\text { relacionamento, volume, } \\
\text { preço, tipo de produto)? } \\
\text { Qual é a classificação } \\
\text { da organização foco } \\
\text { para sua empresa? }\end{array}$} & $\begin{array}{l}\text { A empresa utiliza-se da curva ABC e da relevância } \\
\text { do produto na cadeia produtiva, e procura } \\
\text { consolidar a relação cada vez mais, buscando } \\
\text { atingir sempre a satisfação de ambas as partes. }\end{array}$ \\
\hline Depto. Compras & & $\begin{array}{l}\text { Os fornecedores são classificados pela Curva ABC } \\
\text { dos produtos (volume, preço). }\end{array}$ \\
\hline Cliente & & $\begin{array}{l}\text { Um fornecedor novo para passar a ser } \\
\text { homologado, deve ter suas condições comerciais } \\
\text { acertadas e após isso ele vai passar pelo processo } \\
\text { de entrega de amostras, lote piloto e ai sim farão } \\
\text { parte do grupo de fornecedores homologados. A } \\
\text { cada semestre é avaliado a quantidade de lotes } \\
\text { aprovados e pontualidade. Caso ele tenha uma } \\
\text { nota adequada, ele continuará fazendo parte do } \\
\text { grupo, caso sua nota seja regular, ele terá } 30 \text { dias } \\
\text { para apresentar um plano de melhoria. No caso de } \\
\text { nota abaixo do esperado ele automaticamente será } \\
\text { eliminado da lista de fornecedores. }\end{array}$ \\
\hline $\begin{array}{c}\text { Gerência } \\
\text { Administrativa }\end{array}$ & \multirow[t]{3}{*}{$\begin{array}{l}\text { A empresa classifica os } \\
\text { clientes? Como é feita } \\
\text { essa classificação (inter- } \\
\text { relação, tempo de } \\
\text { relacionamento, volume, } \\
\text { preço, tipo de produto)? }\end{array}$} & $\begin{array}{c}\text { As mesmas formas da questão acima. Como } \\
\text { buscamos ser atendidos pelos fornecedores, ou } \\
\text { seja, fazemos para o nosso cliente o que queremos } \\
\text { que façam quando estamos desse lado na relação } \\
\text { comercial. }\end{array}$ \\
\hline Fornecedor & & $\begin{array}{l}\text { Sim, a empresa classifica o cliente, pois o objetivo } \\
\text { da empresa é dar lucros absolutos. A empresa esta } \\
\text { com foco em uma linha especial de produtos. } \\
\text { Procuramos fazer o que ninguém faz para ganhar } \\
\text { em volume, preço, e relacionamento. }\end{array}$ \\
\hline Depto. Comercial & & $\begin{array}{c}\text { São classificados pelo canal de distribuição, ou } \\
\text { seja, se são montadores, distribuidores, lojistas, } \\
\text { etc. Outra classificação utilizada é o da curva ABC } \\
\text { (\% em faturamento). }\end{array}$ \\
\hline Cliente & \multirow{2}{*}{$\begin{array}{l}\text { Essa classificação serve } \\
\text { para a empresa decidir } \\
\text { projetos de parceria? Se } \\
\text { sim, a abrangência } \\
\text { dessa parceria com a }\end{array}$} & $\begin{array}{l}\text { Esta classificação serve para que nosso sistema de } \\
\text { qualidade não seja afetado, o fornecedor } \\
\text { atendendo estes requisitos ele sempre fará parte da } \\
\text { lista de homologados. }\end{array}$ \\
\hline Depto. Comercial & & Sim, todas as decisões são tomadas sobre análise \\
\hline
\end{tabular}




\section{Os fatores Condicionantes da Gestão de custos Interorganizacionais em uma Indústria metalúrgica da cidade de Rio do Sul - SC Sabrina do Nascimento, Alexandre Matos Pereira, Jorge Eduardo Scarpin}

\begin{tabular}{|c|c|c|}
\hline & \multirow{3}{*}{$\begin{array}{l}\text { organização foco: } \\
\text { pesquisa, tecnologia, } \\
\text { desenvolvimento, } \\
\text { projeto, finanças, } \\
\text { planejamento } \\
\text { colaborativo, outros? }\end{array}$} & dessas classificações. \\
\hline Fornecedor & & $\begin{array}{l}\text { Sim estamos sempre pesquisando e procurando } \\
\text { melhorar a tecnologia da empresa buscando } \\
\text { maquinas de ponta e com recursos superiores aos } \\
\text { dos outros. } \\
\text { Outra coisa muito importante que se faz é trabalhar } \\
\text { em conjunto com o cliente para que não só um } \\
\text { ganhe, mas os dois possam se dar bem. }\end{array}$ \\
\hline Depto. Compras & & $\begin{array}{l}\text { Sim. Esta classificação nos auxilia na busca de } \\
\text { parcerias. Estas parcerias abrangem alguns } \\
\text { desenvolvimentos e o fornecimento. }\end{array}$ \\
\hline Cliente & $\begin{array}{l}\text { Os produtos comprados } \\
\text { da organização foco são } \\
\text { diferenciados ou } \\
\text { existem custos de } \\
\text { mudança, caso a } \\
\text { empresa queira trocá- } \\
\text { los? Quais são? }\end{array}$ & $\begin{array}{l}\text { Os produtos adquiridos pela Royal ciclo são } \\
\text { produtos com padrão de mercado. }\end{array}$ \\
\hline Fornecedor & $\begin{array}{l}\text { Os insumos vendidos } \\
\text { para a organização foco } \\
\text { são diferenciados ou } \\
\text { existem custos de } \\
\text { mudança, caso a } \\
\text { empresa queria trocá- } \\
\text { los? Quais são? }\end{array}$ & $\begin{array}{l}\text { Os insumos que a empresa usa são tradicionais de } \\
\text { mercado, não tendo muita abrangência. }\end{array}$ \\
\hline $\begin{array}{c}\text { Gerência } \\
\text { Administrativa }\end{array}$ & \multirow{2}{*}{$\begin{array}{l}\text { Os insumos adquiridos } \\
\text { dos principais } \\
\text { fornecedores são } \\
\text { diferenciados ou } \\
\text { existem custos de } \\
\text { mudança, caso a } \\
\text { empresa queira trocá- } \\
\text { los? Quais são as } \\
\text { diferenças e os custos } \\
\text { de mudança? }\end{array}$} & $\begin{array}{l}\text { Alguns produtos são específicos, no caso de } \\
\text { mudança temos diferenças a considerar no quesito } \\
\text { qualidade e provavelmente não atingiremos os } \\
\text { níveis atuais. Podendo em alguns casos ter o custo } \\
\text { inferior, por ter qualidade inferior também. }\end{array}$ \\
\hline Depto. Compras & & $\begin{array}{c}\text { Sim. São insumos diferenciados. É necessário fazer } \\
\text { estudos para chegar a estes valores e quais as } \\
\text { diferenças específicas. }\end{array}$ \\
\hline $\begin{array}{c}\text { Gerência } \\
\text { Administrativa }\end{array}$ & \multirow[t]{2}{*}{$\begin{array}{l}\text { O produto da empresa é } \\
\text { diferenciado ou existiria } \\
\text { custo de mudança, caso } \\
\text { os clientes queiram } \\
\text { comprar de outra } \\
\text { empresa? Quais? }\end{array}$} & $\begin{array}{c}\text { Alguns produtos são diferenciados, mais a maioria } \\
\text { não, o diferencial que a empresa possui hoje no } \\
\text { mercado é a qualidade do produto, pois os } \\
\text { concorrentes são externos, porém com qualidade } \\
\text { muito inferior. }\end{array}$ \\
\hline Depto. Comercial & & $\begin{array}{c}\text { A empresa possui um mix de produtos muito } \\
\text { grande, a maioria desses produtos são } \\
\text { "commodities", diferenciados dos concorrentes pela } \\
\text { qualidade, porém, a empresa está sempre } \\
\text { investindo para inovar e diferenciar seus produtos. } \\
\text { Um exemplo disso é a importação de um novo } \\
\text { carrossel da Itália que fabrica selins de PVC, } \\
\text { exclusividade no Brasil. }\end{array}$ \\
\hline $\begin{array}{c}\text { Cliente } \\
\text { Fornecedor }\end{array}$ & $\begin{array}{l}\text { Existem poucos ou } \\
\text { muitos fornecedores }\end{array}$ & $\begin{array}{c}\text { Existem vários fornecedores destes produtos. } \\
\text { Os principais fornecedores são Belgo e Gerdau e }\end{array}$ \\
\hline
\end{tabular}




\section{Os fatores Condicionantes da Gestão de custos Interorganizacionais em uma Indústria metalúrgica da cidade de Rio do Sul - SC Sabrina do Nascimento, Alexandre Matos Pereira, Jorge Eduardo Scarpin}

\begin{tabular}{|c|c|c|}
\hline & $\begin{array}{l}\text { para os principais } \\
\text { produtos fornecidos pela } \\
\text { organização foco? }\end{array}$ & $\begin{array}{l}\text { não tem muitas outras opções de compras de } \\
\text { matérias-primas. }\end{array}$ \\
\hline $\begin{array}{c}\text { Gerência } \\
\text { Administrativa }\end{array}$ & \multirow{2}{*}{$\begin{array}{l}\text { Existem poucos ou } \\
\text { muitos fornecedores } \\
\text { para os principais } \\
\text { insumos adquiridos de } \\
\text { terceiros? }\end{array}$} & $\begin{array}{c}\text { Poucos e em alguns casos somente fornecedores } \\
\text { exclusivos ou únicos. }\end{array}$ \\
\hline Depto. Compras & & $\begin{array}{l}\text { Existem poucos. } \\
\end{array}$ \\
\hline $\begin{array}{c}\text { Gerência } \\
\text { Administrativa }\end{array}$ & \multirow{2}{*}{$\begin{array}{l}\text { Existem poucos ou } \\
\text { muitos concorrentes } \\
\text { para o produto vendido } \\
\text { pela empresa? }\end{array}$} & $\begin{array}{c}\text { No mercado nacional, muito pouco, no internacional } \\
\text { a concorrência é mais acirrada. }\end{array}$ \\
\hline Depto. Comercial & & $\begin{array}{l}\text { Existem muitos concorrentes nacionais além dos } \\
\text { produtos chineses, que tem o custo muito baixo. }\end{array}$ \\
\hline Cliente & \multirow[b]{2}{*}{$\begin{array}{c}\text { Existe estabilidade no } \\
\text { relacionamento com a } \\
\text { organização foco? } \\
\text { Como (contratos de } \\
\text { médio e longo prazo, } \\
\text { acordos comerciais, } \\
\text { etc.)? }\end{array}$} & Existe um relacionamento de longa data. \\
\hline Fornecedor & & $\begin{array}{l}\text { Não, os acordos são feitos com a boa relação de } \\
\text { comercio que a empresa adota para garantir um } \\
\text { cliente fiel e a própria ser competitiva. }\end{array}$ \\
\hline $\begin{array}{c}\text { Gerência } \\
\text { Administrativa }\end{array}$ & \multirow{2}{*}{$\begin{array}{l}\text { Existe estabilidade no } \\
\text { relacionamento com } \\
\text { seus fornecedores? } \\
\text { Como (contratos de } \\
\text { médio e longo prazo, } \\
\text { acordos comerciais, } \\
\text { etc.)? }\end{array}$} & $\begin{array}{c}\text { Existem acordos comerciais verbais que viabilizem } \\
\text { esta estabilidade. }\end{array}$ \\
\hline Depto. Compras & & $\begin{array}{l}\text { Existe estabilidade no relacionamento com os } \\
\text { fornecedores. Mantemos acordos comerciais. }\end{array}$ \\
\hline $\begin{array}{c}\text { Gerência } \\
\text { Administrativa }\end{array}$ & \multirow{2}{*}{$\begin{array}{l}\text { Existe estabilidade no } \\
\text { relacionamento com } \\
\text { seus clientes? Como } \\
\text { (contratos de médio e } \\
\text { longo prazo, acordos } \\
\text { comerciais, etc.)? }\end{array}$} & $\begin{array}{l}\text { Sim. Há monitoramento constante nas relações } \\
\text { comerciais para que haja uma estabilidade. }\end{array}$ \\
\hline Depto. Comercial & & $\begin{array}{c}\text { Sim, o relacionamento com o cliente é priorizado e } \\
\text { existe um acordo comercial com os maiores } \\
\text { clientes. }\end{array}$ \\
\hline Depto. Compras & $\begin{array}{l}\text { Existe estabilidade no } \\
\text { relacionamento com } \\
\text { seus fornecedores? } \\
\text { Como (contratos de } \\
\text { médio e longo prazo, } \\
\text { acordos comerciais, } \\
\text { etc.)? }\end{array}$ & $\begin{array}{l}\text { Existe estabilidade no relacionamento com os } \\
\text { fornecedores. Mantemos acordos comerciais. }\end{array}$ \\
\hline Cliente & \multirow{2}{*}{$\begin{array}{l}\text { A empresa confia na } \\
\text { organização foco? } \\
\text { Como a empresa tem a } \\
\text { sensibilidade desta } \\
\text { confiança (contar com } \\
\text { futuras negociações, } \\
\text { cumprimento de } \\
\text { promessas, honestidade } \\
\text { aos problemas que } \\
\text { surgem)? }\end{array}$} & $\begin{array}{l}\text { Sim confia. A empresa é muito conhecida neste } \\
\text { mercado e sempre tem boas referências. }\end{array}$ \\
\hline Fornecedor & & $\begin{array}{l}\text { Temos plena confiança em toda a organização e a } \\
\text { confiança é conquistada por meio de indicadores } \\
\text { que mostram para nós o potencial que temos em } \\
\text { mudar e fazer as coisas acontecerem, para que } \\
\text { quando os problemas surjam já estejamos prontos } \\
\text { para combater e poder também dizer que eu errei. }\end{array}$ \\
\hline Gerência & A empresa confia em & A empresa confia, e antes de uma efetiva compra \\
\hline
\end{tabular}


Os fatores Condicionantes da Gestão de custos Interorganizacionais em uma Indústria

metalúrgica da cidade de Rio do Sul - SC

Sabrina do Nascimento, Alexandre Matos Pereira, Jorge Eduardo Scarpin

\begin{tabular}{|c|c|c|}
\hline Administrativa & \multirow[b]{2}{*}{$\begin{array}{c}\text { seus principais } \\
\text { fornecedores? Como a } \\
\text { empresa tem a } \\
\text { sensibilidade desta } \\
\text { confiança (contar com } \\
\text { futuras negociações, } \\
\text { cumprimento de } \\
\text { promessas, honestidade } \\
\text { aos problemas que } \\
\text { surgem)? }\end{array}$} & $\begin{array}{c}\text { há uma qualificação do fornecedor para que } \\
\text { possamos confiar na relação. }\end{array}$ \\
\hline Depto. Compras & & $\begin{array}{l}\text { Sim. Confia, com base no histórico de } \\
\text { fornecimento. }\end{array}$ \\
\hline $\begin{array}{c}\text { Gerência } \\
\text { Administrativa }\end{array}$ & \multirow[b]{2}{*}{$\begin{array}{c}\text { A empresa confia em } \\
\text { seus principais clientes? } \\
\text { Como a empresa tem a } \\
\text { sensibilidade desta } \\
\text { confiança (contar com } \\
\text { futuras negociações, } \\
\text { cumprimento de } \\
\text { promessas, honestidade } \\
\text { aos problemas que } \\
\text { surgem?) }\end{array}$} & $\begin{array}{l}\text { Sim, porém está sempre atenta às variações nas } \\
\text { compras para que esta confiança seja plena. }\end{array}$ \\
\hline Depto. Comercial & & $\begin{array}{l}\text { Sim, por meio do relacionamento de longa duração } \\
\text { e pela transparência pela qual procuramos sempre } \\
\text { buscamos nos negócios realizados. }\end{array}$ \\
\hline
\end{tabular}

Quadro 2 - Respostas relacionadas aos fatores condicionantes Nível de Relacionamento e Tipo de Cadeia

Fonte: Adaptado de Souza (2008).

No Quadro 2, verifica-se que a empresa analisada utiliza a curva $A B C$ dos produtos (volume e preço) e a relevância do produto na cadeia produtiva para seleção dos seus fornecedores, sendo que as relações comerciais são estabelecidas apenas verbalmente e por meio de acordo não sendo utilizados contratos formais. Observa-se, ainda, que há uma relação de confiança entre a empresa analisada e seus clientes e fornecedores consolidada pelo tempo de experiência no mercado, reputação e qualidade dos produtos. Cabe mencionar, também, que a empresa analisada não possui muita concorrência no mercado nacional apenas a concorrência dos produtos chineses, porém no mercado internacional a concorrência é mais acirrada.

No que tange ao fator condicionante nível de relacionamento a empresa estudada possui um bom nível de relacionamento com seus clientes e fornecedores, sendo considerada como nível principal, onde as relações de interdependência são maiores que no nível auxiliar. Neste nível, a empresa estabelece um relacionamento 
que envolve além do processo de fabricação o fornecedor, envolve-se na etapa de desenvolvimento e criação do produto demonstrando parceiras mais duradouras. Entretanto, a empresa não possui restrições tecnológicas que não repassa aos mesmos, sendo recomendável a aplicação da GCI nestas situações. No que concerne ao tipo de cadeia a empresa enquadra-se como democracia, pois atua principalmente no contexto internacional onde a concorrência é bastante acirrada e esta situação acaba por se estender ao mercado nacional.

\subsection{Mecanismos}

Nesta seção, discute-se sobre o fator condicionante mecanismos, sendo que este diz respeito aos instrumentos utilizados pela empresa para o controle da $\mathrm{GCl}$ que buscam auxiliar na gestão dos custos entre as empresas para conseguir orientar, controlar, medir, informar, além de buscar transparência por meio da utilização da $\mathrm{GCl}$ (SOUZA, 2008). O Quadro 3 apresenta as respostas dos entrevistados sobre este fator condicionante. 


\section{Os fatores Condicionantes da Gestão de custos Interorganizacionais em uma Indústria metalúrgica da cidade de Rio do Sul - SC Sabrina do Nascimento, Alexandre Matos Pereira, Jorge Eduardo Scarpin}

\begin{tabular}{|c|c|c|}
\hline RESPONDENTE & PERGUNTA & RESPOSTA \\
\hline Cliente & \multirow{2}{*}{$\begin{array}{l}\text { A empresa coopera com a } \\
\text { organização foco (troca de } \\
\text { informação, metas de redução de } \\
\text { custos, planejamento em conjunto, } \\
\text { investimento em conjunto)? }\end{array}$} & Sim. \\
\hline Fornecedor & & $\begin{array}{l}\text { Ainda não recebemos visita da empresa } \\
\text { em questão, mas nós já fizemos muitas } \\
\text { visitas e fizemos muitas melhorias juntos } \\
\text { com a equipe de produção e projetos para } \\
\text { facilitar o processo produtivo em questão. }\end{array}$ \\
\hline Depto. Comercial & $\begin{array}{l}\text { A empresa coopera com seus } \\
\text { principais clientes (troca de } \\
\text { informações, metas de redução de } \\
\text { custos, planejamento em conjunto, } \\
\text { investimento em conjunto)? E os } \\
\text { clientes fazem o mesmo? }\end{array}$ & $\begin{array}{c}\text { Sim, qualquer alteração em nossos } \\
\text { produtos, preços, política de vendas, etc. } \\
\text { os clientes são informados. Assim a } \\
\text { empresa tem que ser flexível quando essas } \\
\text { mudanças podem causar algum problema } \\
\text { a eles. }\end{array}$ \\
\hline Depto. Compras & \multirow[b]{2}{*}{$\begin{array}{l}\text { A empresa coopera com seus } \\
\text { principais fornecedores (troca de } \\
\text { informação, metas de redução de } \\
\text { custos, planejamento em conjunto, } \\
\text { investimento em conjunto)? E os } \\
\text { fornecedores fazem o mesmo? }\end{array}$} & Sim. \\
\hline $\begin{array}{c}\text { Gerência } \\
\text { Administrativa }\end{array}$ & & $\begin{array}{l}\text { Sim. Sempre após o planejamento para o } \\
\text { próximo período há reuniões com os } \\
\text { mesmos para exposição dos objetivos para } \\
\text { que haja sintonia nas duas pontas da } \\
\text { relação. A busca por parte deles é } \\
\text { recíproca e isto tem tornado cada vez mais } \\
\text { sólidas o tratamento com clientes e } \\
\text { fornecedores. }\end{array}$ \\
\hline Cliente & $\begin{array}{l}\text { A empresa ajuda a organização } \\
\text { foco encontrar maneiras de } \\
\text { conciliar suas habilidade e } \\
\text { coordenar esforços de modo a } \\
\text { alcançarem as metas? Como? }\end{array}$ & $\begin{array}{l}\text { Sim. Quando não consegue atender nossa } \\
\text { necessidade total, sempre tentam atender } \\
\text { de alguma maneira para que nosso produto } \\
\text { final não seja prejudicado. }\end{array}$ \\
\hline Depto. Comercial & $\begin{array}{c}\text { A empresa ajuda seus clientes a } \\
\text { encontrar maneiras de conciliar } \\
\text { suas habilidades e coordenar } \\
\text { esforços de modo a alcançarem as } \\
\text { metas? Como? }\end{array}$ & $\begin{array}{l}\text { Sim, buscando o atendimento sempre } \\
\text { dentro das necessidades de cada cliente. }\end{array}$ \\
\hline Depto. Compras & $\begin{array}{l}\text { A empresa ajuda seus ajuda seus } \\
\text { fornecedores a encontrar maneiras } \\
\text { de conciliar suas habilidades e } \\
\text { coordenar esforços de modo a } \\
\text { alcançarem as metas? Como? }\end{array}$ & $\begin{array}{l}\text { Sim. Programando as compras com } \\
\text { antecedência, formalizando alterações e } \\
\text { negociando sempre. }\end{array}$ \\
\hline $\begin{array}{c}\text { Gerência } \\
\text { Administrativa }\end{array}$ & $\begin{array}{c}\text { A empresa ajuda seus } \\
\text { fornecedores e clientes a encontrar } \\
\text { maneiras de conciliar suas } \\
\text { habilidades e coordenar esforços } \\
\text { de modo a alcançarem as metas? } \\
\text { Como? }\end{array}$ & $\begin{array}{l}\text { Sim, por meio de sensibilidades do } \\
\text { mercado e busca de informações para que } \\
\text { haja harmonia nos pensamentos acerca do } \\
\text { mercado. }\end{array}$ \\
\hline Cliente & \multirow{2}{*}{$\begin{array}{l}\text { Se existir projetos de parcerias } \\
\text { com a organização foco, como a } \\
\text { empresa mede os resultados } \\
\text { alcançados e avalia se a parceria } \\
\text { foi bem sucedida? Quando da } \\
\text { existência de um ganho como é } \\
\text { realizada a divisão? }\end{array}$} & $\begin{array}{l}\text { A parceria é medida por meio do cálculo do } \\
\text { IQF (Índice de qualidade do Fornecedor), } \\
\text { feita semestralmente. }\end{array}$ \\
\hline Fornecedor & & $\begin{array}{l}\text { A empresa mede seus resultados por meio } \\
\text { de indicadores para ver se seus objetivos } \\
\text { foram alcançados e se suas metas estão } \\
\text { sendo cumpridas. }\end{array}$ \\
\hline
\end{tabular}


Os fatores Condicionantes da Gestão de custos Interorganizacionais em uma Indústria metalúrgica da cidade de Rio do Sul - SC Sabrina do Nascimento, Alexandre Matos Pereira, Jorge Eduardo Scarpin

\begin{tabular}{|c|c|c|}
\hline & & $\begin{array}{l}\text { A empresa ainda não adotou a divisão de } \\
\text { um ganho para seus colaboradores. }\end{array}$ \\
\hline Depto. Comercial & $\begin{array}{c}\text { Se existir projetos de parcerias } \\
\text { com clientes, como a empresa } \\
\text { mede os resultados alcançados e } \\
\text { avalia se a parceria foi bem } \\
\text { sucedida? Quando da existência } \\
\text { de um ganho como é realizada a } \\
\text { divisão? }\end{array}$ & Não há. \\
\hline $\begin{array}{c}\text { Gerência } \\
\text { Administrativa }\end{array}$ & \multirow{2}{*}{$\begin{array}{l}\text { Se existir projetos de parcerias } \\
\text { com fornecedores, como a } \\
\text { empresa mede os resultados } \\
\text { alcançados e avalia se a parceira } \\
\text { foi bem sucedida? Quando da } \\
\text { existência de um ganho como é } \\
\text { realizada a divisão? }\end{array}$} & Não há parcerias firmadas. \\
\hline Depto. Compras & & Não respondeu. \\
\hline
\end{tabular}

Quadro 3 - Respostas relacionadas ao fator condicionante Mecanismos Fonte: Adaptado de Souza (2008).

Por meio das informações dispostas no Quadro 3, nota-se que ocorre uma cooperação de informações entre as empresas (empresa analisada, fornecedor e cliente), porém esta se dá de maneira informal. Infere-se ainda a partir das respostas, que a empresa analisada estabelece um bom relacionamento com seus cliente e fornecedores, conseguindo coordenar esforços a fim de satisfazer as necessidades de todos os envolvidos, porém observa-se que não existem projetos de parceria entre as empresas. Cabe mencionar, ainda, que o cliente utiliza como mecanismo de controle o cálculo do IQF (índice de Qualidade do Fornecedor) para auferir o desempenho da empresa analisada semestralmente e o fornecedor realiza o mesmo monitoramente por meio de indicadores próprios. Assim, percebe-se que a empresa estudada faz uso apenas das demonstrações financeiras mensais para auferir o desempenho de seus parceiros e a gestão de seus custos, não dispondo de outros mecanismos para tal controle e colhendo as informações de seus concorrentes por meio da internet e jornais.

Nesse sentido, infere-se que a empresa utiliza como mecanismo os capacitores que conforme evidenciado na teoria são artefatos que fornecem capacidade, competência e possibilidades com o objetivo de suprir as dificuldades no processo de implementação da $\mathrm{GCl}$ e ajudar a solucionar os problemas encontrados (SOUZA, 
Os fatores Condicionantes da Gestão de custos Interorganizacionais em uma Indústria

metalúrgica da cidade de Rio do Sul - SC

Sabrina do Nascimento, Alexandre Matos Pereira, Jorge Eduardo Scarpin

2008). Esta situação é visualizada na empresa analisada, quando ocorrem as reuniões entre clientes, fornecedores e a metalúrgica analisada, além das visitas realizadas pelos fornecedores realizando o intercâmbio de profissionais e o desenvolvimento em conjunto que contribuem no processo de inovação tecnológica. Esses resultados contrapõem os achados de Souza (2008) que detectou mecanismos disciplinadores quando analisou as empresas do segmento de transporte aéreo e alimentício. Para tanto, percebe-se, ainda, que a empresa analisada poderia utilizar os mecanismos disciplinadores e incentivadores, tendo em vista que estes não foram detectados.

\section{CONSIDERAÇÕES FINAIS}

Esta pesquisa objetivou identificar os fatores condicionantes da Gestão de Custos Interorganizacionais $(\mathrm{GCl})$ em uma indústria metalúrgica na cidade de Rio do Sul em Santa Catarina. Na metodologia, realizou-se um estudo de caso, por meio de uma pesquisa descritiva com abordagem qualitativa. Na coleta de dados utilizou-se de um conjunto de cinco questionários propostos por Souza (2008). Resgata-se, a seguir, a indagação central desta pesquisa: Quais os fatores condicionantes da Gestão de Custos Interorganizacionais em uma empresa metalúrgica? Em resposta à indagação foi possível constatar que:

No fator condicionante produtos a empresa analisada possui alta funcionalidade atribuída aos mesmos, tendo em vista o fator tecnológico e a qualidade, sendo esta sua principal fonte de diferenciação frente aos seus concorrentes. No que se refere à margem, a empresa analisada utiliza apenas os demonstrativos financeiros fornecidos pela contabilidade para tomada de decisão, não dispondo de um controle de custos mais específico. Entretanto, em relação ao fator condicionante componentes, verifica-se que o índice de valor é percebido pelos clientes por meio do custo $\mathrm{x}$ benefício proporcionado pelos componentes utilizados nos produtos com alto padrão tecnológico. Ressalta-se, ainda, que a empresa apresenta restrições tecnológicas com relação aos 
seus produtos principalmente pela tecnologia italiana advinda de sua parceria corporativa. Estes achados corroboram com Souza (2008), que detectou o alto nível de funcionalidade nas empresas analisadas em sua pesquisa tendo em vista as restrições tecnológicas impostas pelas mesmas.

No que concerne aos fatores condicionantes nível de relacionamento e tipo de cadeia, percebe-se que a empresa possui um nível de relacionamento do tipo principal, que estabelece relações com o fornecedor em todo processo de fabricação, desenvolvimento e criação do produto por meio de parcerias de longo prazo. Entretanto, a empresa não deixa de lado as restrições tecnológicas que envolvem o produto e não compartilha todas as informações do processo com terceiros. Para tanto, no tipo de cadeia a empresa enquadra-se na tipificação democracia, pois não realiza imposição de poder perante seus concorrentes principalmente no contexto internacional. Assim, verifica-se que a implantação da GCl torna-se recomendável nesta situação. Estes resultados corroboram com os achados de Souza (2008) que detectou nas empresas que analisou o tipo de cadeia democracia, tendo em vista a concorrência do mercado onde atuavam.

Contudo, no fator condicionante mecanismos a empresa faz uso dos mecanismos do tipo capacitores que envolvem seus clientes e fornecedores no intercâmbio de informações e o desenvolvimento conjunto dos produtores com vistas a contribuírem no processo de inovação tecnológica. Cabe mencionar que a empresa analisada não utiliza artefatos específicos para a gestão de seus custos. Assim, percebe-se que ela poderia fazer uso dos mecanismos disciplinadores e incentivadores. Estes resultados contrapõem os achados de Souza (2008) que encontrou apenas os mecanismos disciplinadores nas empresas que analisou.

Por fim, conclui-se que os fatores condicionantes da $\mathrm{GCl}$ foram encontrados na empresa analisada, sendo recomendável a sua aplicação e estimulação por meio dos mecanismos que auxiliem no controle dos custos e na sua redução, fortalecendo as relações e parcerias entre as empresas que compõem a cadeia de valor. Sendo assim, 
sugere-se para futuras pesquisas: (i) a réplica desta pesquisa em anos posteriores a fim de identificar a evolução dos fatores condicionantes da $\mathrm{GCl}$ na empresa analisada; e (ii) a identificação dos fatores condicionantes da $\mathrm{GCl}$ em outras empresas do mesmo segmento.

\section{REFERÊNCIAS}

AGUIAR, A.B.; ROCHA, W. (2007). Uma Análise da Complementariedade entre Gestão Interorganizacional de Custos e Open-Book Accounting. In: Congresso de Controladoria e Finanças, 7, São Paulo, 2007. Anais... São Paulo, USP.

AGUIAR, A.B.; REZENDE, A.J.; ROCHA, W. Uma Análise da Complementariedade entre Gestão Interorganizacional de Custos e Open-Book Accounting. Base - Revista de Administração e Contabilidade da Unisinos, 5(1):66-76.

BITTI, E.J.S.; AQUINO, A.C.B.; PAGLIARUSSI, M.S. (2007). Custos Interorganizacionais: o efeito dos custos de monitoramento na decisão de mix de redes franqueadas brasileiras. In: Congresso de Controladoria e Finanças, 7., 2007. São Paulo. Anais... São Paulo, USP.

COOPER, R.;e SLAGMULDER, R. (2004). Interorganizational cost management and relational context. Accounting, Organizations and Society, 29(1)1-26.

GIL, A.C. (1999). Métodos e técnicas de pesquisa social. São Paulo, Atlas.

MARTINS, G.A.; THEÓPHILO, C.R. (2007). Metodologia da Investigação Científica para Ciências Sociais Aplicadas. São Paulo, Atlas.

MEIRA, J.M.; WANDERLEY, C.A; MIRANDA, L.C. (2005). O papel da troca de informações interorganizacionais na performance da cadeia de produção avícola brasileira. Custos e @gronegócio online. 1(1): 21-41.

OLIVEIRA, A.B.S. (2003). (Coordenação). Métodos e técnicas de pesquisa em contabilidade. São Paulo, Saraiva.

RICHARDSON, R.J. (1999). Pesquisa social: métodos e técnicas. São Paulo, Atlas.

SARAIVA JÚNIOR A.F.; RODRIGUES, M.V.; COSTA, R.P. (2009). Modelo de determinação da margem de contribuição de produtos com variabilidade de preços e 
custos diretos unitários: uma aplicação em uma indústria de produtos plásticos. ABCustos - Associação Brasileira de Custos, 4(3):33-61.

SHANK, J.K..; GOVINDARAJAN, V. (1997). A revolução dos custos: como reinventar e redefinir sua estratégia de custos para vencer em mercados crescentemente competitivos. Rio de Janeiro, Elsevier.

SOUZA, B.C. (2008). Fatores Condicionantes da Gestão de Custos Interorganizacionais. São Paulo, SP. (Dissertação de mestrado). Universidade de São Paulo - USP, 150p.

SOUZA, B.C.; ROCHA, W. (2008). Fatores Condicionantes da Gestão de Custos Interorganizacionais. In: Congresso de Controladoria e Finanças, 8., São Paulo. Anais... São Paulo, USP.

SOUZA, B.C.; ROCHA, W. (2010). Gestão de Custos Interorganizacionais: ações coordenadas entre clientes e fornecedores para otimizar resultados. Revista MundoLogística, 12:65-74.

Data de Submissão: $17 / 11 / 2010$

Data de Aceite: 04/06/2012 